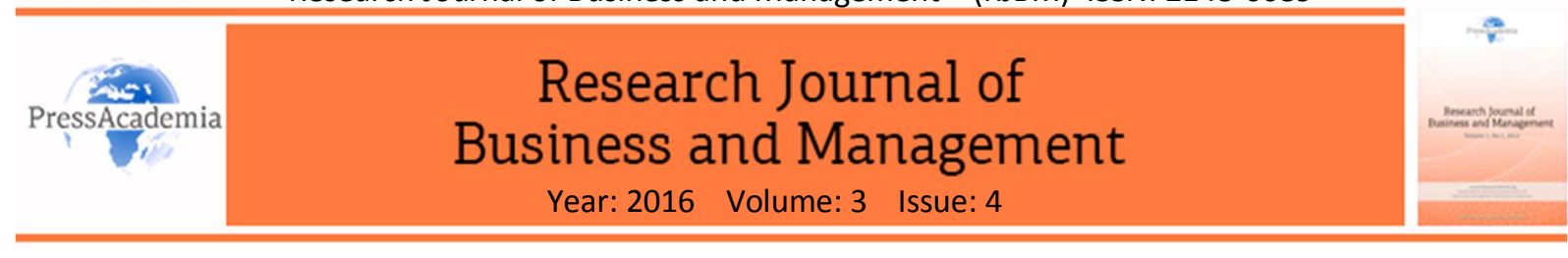

\title{
VIGNETTE DEVELOPMENT FOR DETERMINING THE PERSONAL CHARACTERISTICS OF RESILIENT LEADERS
}

\author{
DOI: 10.17261/Pressacademia.2016.352
}

\section{Emel Esen}

Yildiz Technical University, emeloz@yildiz.edu.tr

\begin{abstract}
Resiliency have a meaning of being flexible, adapting to change, having a strong awareness, being optimistic and bounce back from risk, stress or uncertainty. The purpose of this study is to determine the personal characteristics of resilient leaders by using vignettes. The approach of this research is qualitative which was designed in two steps (structured interviews and vignette development). Based on the data gathering from interviews, short vignettes were designed for future research purposes in this area. It was found that three personality characteristics (optimism, self-efficacy and self-esteem) will determine the resilient leader behavior in the sample of basketball organization. There are several limitations that should be associated for this study. Firstly, structured interviews have the low popularity and participation. Secondly, as suggesting vignettes for this study, there is a lack of statistical data. This study is valua ble to understand the relationship between personality characteristics and resilient leader behavior in sports area.
\end{abstract}

Keywords: Personality characteristics, resilient leader behavior, psychological capital

JEL Classification: M10, M14

\section{INTRODUCTION}

Number of studies in psychology and organizational behavior has become interested in understanding and examining of positive aspects of people. Positive psychology and positive organizational behavior concerns the application of psychology to improve the quality of work life and to protect and promote the safety, health, and well-being of workers. Psychological capital with components of hope, self-efficacy, optimism, and resiliency has recently emerged as a core construct in taking positive psychology to the workplace (Luthans, Avey and Patera, 2008).

Among the four components of the psychological capital in the positive organizational behavior, psychological resiliency is one of the most popular interest areas. Resiliency have a meaning of being flexible, adapting to change, having a strong awareness, being optimistic and bounce back from risk, stress or uncertainty. Therefore, personality factors have an influence on resilient leader behavior. For example optimists who interpret bad events as being only temporary may be identified as resilient individual. Individual with selfawareness know what they need, so they tend to cope with and handle stress. People with high internal locus of control can control their environment; they may be able to affect the situation. Also, social competence, extraversion, autonomy, problem solving can all be attributes of resilient leaders (Luthans, Luthans and Luthans, 2004).

This article investigates the personal characteristics of resilient leaders by developing vignettes in the sample of basketball coaches and coach assistants. In the first part of this article, the definition of resiliency was given, the effect of personal characteristics on resilient leader behavior were discussed. In the methodology, firstly structured interviews were conducted to determine which characteristics are important to be resilient in leading teams and secondly three specific personal characteristics as optimistic, self-esteem and self-efficacy were chosen and manipulated in developing the vignettes by the researcher for future studies. In the first part 
of this study, theoretical framework was given about resiliency, and then the methodology and research design was discussed.

\section{LITERATURE REVIEW}

\subsection{The Definition of Resiliency}

Resiliency was discussed many years ago as a personality trait related to adaptability and coping especially in clinical research on children and their parents. This researchers in this area identified resilient individual's qualities, understanding come up with stress and change and motivational factors that foster them (Luthans, Vogelgesang and Lester, 2006). From a clinical psychology perspective, Masten and Reed (2002), define resiliency as a class of phenomena characterized by patterns of positive adaptation in the context of significant adversity or risk (Luthans, Youssef and Avolio, 2006). Although resiliency research has only recently drawn the attention of criminologists, its foundation can be traced to work completed by developmental psychologists and developmental psychopathologists several decades ago (Hartman et al., 2009).

POB (Positive Organizational Behavior) has adopted a cross-disciplinary perspective, drawing from the established theory building and empirical findings in clinical and developmental psychology (Youssef and Luthans, 2007). Positive psychologists defined resiliency as what is right and good about people (Luthans, Vogelgesang and Lester, 2006). They defined resiliency in workplace as a criteria-meeting component of Psychological Capital (Luthans, Youssef and Avolio, 2006). Luthans (2002) defined resiliency as "the positive psychological capacity to rebound, to 'bounce back' from adversity, uncertainty, conflict, failure or even positive change, progress and increased responsibility" (Siu, 2009). In positive psychology, resilience is characterized by positive coping and adaptation in the face of significant risk or adversity (Luthans et al., 2007).

American Heritage Dictionary (2005) defines it as "the ability to recover quickly from illness, depression, change, or misfortune (Earvolino-Ramirez, 2007). The Online Oxford Dictionary defines resilience as, 'the ability of a substance or object to spring back into shape' or 'the capacity to recover quickly from difficulties; toughness.' (Robertson and Cooper, 2013). The essence of resilience centers around a quick recovery from shock, illness or adversity (Vickers and Kouzmin, 2001)

\subsection{Personality Factors and Resilient Leader Behavior}

Many theorists believe that some people are born resilient, but also some empirical evidences show that resilience can be learned (Coutu, 2002). If a person wants to develop his/her resiliency, it is need to modify his/her actions and thoughts in accepting change, learning continuously, self-empowerment, personal identity and network (Pulley and Wakefield, 2002). It is obvious that resilient leaders bounce back without more effort (Boin, Michel and Eeten, 2014). Resilience is so such a valuable goal that leaders must commit themselves (Hamel and Valikangas, 2003).

There are three characteristics hold true for both resilient leaders and resilient organizations: Optimisim, make meaning and make whatever is at hand (Coutu, 2002). Optimism is correlated positively with extraversion, selfconfidence, self-esteem, repression, self-deception, and positive affect, and negatively with anxiety, neuroticism, self- consciousness (Norem and Chang, 2002). Optimism can contribute to an individual's ability persist at tasks successfully (Harland et al., 2004). Meaning in life (with two components: search for meaning in life and the presence of meaning in life) defined as a sense of purpose that is believed to matter in a way beyond the individual living that life It is associated with psychological well-being and resiliency factor (Kleiman and Beaver, 2013). Makes meaning of the world and meaning process also defined as self-awareness which is about seek feedbacks to improve interactions with others and accurately describes how others view his or her capabilities (Walumbwa et al. , 2008).

According to Patterson and Kelleher (2005), there are six strengths of resilient leaders: Assessing past and current reality, being positive about future possibilities, remaining true to personal values, maintaining personal efficacy, investing personal energy, action on the courage.

Friborg et al (2005) stated that resilient personality profile is related with all the Big Five Factors (Emotional stability, extraversion, openness, agreeableness and conscientiousness). Resilient people are more extroverted 
due to positive social orientation. Extroverts may able to build social assets that can contribute their resiliency (Avey, Luthans and Youssef, 2019). Extraverted people are more likely to offer transformational leadership performance which was defined as charisma, intellectual stimulation and individualized consideration to the employees (Grant, Gino and Hofmann, 2011). Based on the Campbell-Sills, Cohan and Stein's (2006) studies, resilience was negatively associated with neuroticism and positively related to extraversion and conscientiousness.

Resilient leaders are those who have the ability to positively adapt and thrive in very challenging circumstances such as involved in most organizational change (Avey, Wernsing, 2008). They also can teach others to be resilient and their activities can be a model for others to emulate (Stoltz, 2004). On the other hand, authentic leadership is proposed to enhance follower resiliency. (Luthans, Youssef and Avolio, 2006). Avolio, Luthans, and Walumbwa (2004) define authentic leaders as "those who are deeply aware of how they think and behave and are perceived by others as being aware of their own and others' values/moral perspectives, knowledge, and strengths; aware of the context in which they operate; and who are confident, hopeful, optimistic, resilient, and of high moral character" (Avolio and Gardner, 2005). Authentic leadership was conceptualized with five components as self-awareness, relational transparency, internalized regulation, balanced processing of information and positive moral perspective.

Resiliency is definitely understood as a process not only a trait in all business environments. According to Sarkar and Fletcher's study (2013), there is a need to develop a sport-specific measure of resilience (Sarkar and Fletcher, 2013).

\section{DATA AND METHODOLOGY}

The purpose of this study is to determine the characteristics of resilient leaders by developing vignettes. As it was discussed in the literature review, personality characteristics are important determinants of resilient leaders' behavior. In sports organizations, coaches usually feel under pressure and stress with many reasons as work overload, lack of responsibility and knowledge, role ambiguity and conflict and adaptation to new paradigms. Under these circumstances, personality characteristics may have been shown to be related to coaches' resilience level. For this study, research question is that which personality characteristics determine the coaches' psychological resiliency?

To explore and understand the characteristics of resilient managers, vignettes in basketball sports teams are developed. Firstly, structured interview form was designed to understand what team leaders are thinking about psychological resiliency, which attributes are important in resilient leaders' behavior. On the interview form, the purpose of the study was stated and the operational definition of psychological resiliency was given. The resiliency definition stated as: Resiliency is the skill and the capacity to be robust under conditions of stress and change. Participants were asked to answer four questions in this frame of resiliency definition: How do you evaluate your resiliency level?, According to you, which characteristics determine the team leaders' resiliency level? Which conditions/events make you resistant in your sport life?, How your team players are affected by your psychological resiliency level? Secondly, according to the team leaders' evaluations and comments, vignettes are advanced to be used in further studies about leaders' psychological resiliency.

\subsection{Research Design}

This research approach is qualitative which was designed in two steps (structured interviews and vignette development. A vignette is a short scenario or study which is based on fact or fiction. These are especially used in some disciplines as education, psychology and social work (Jones, Taylor and Herber, 2014, 2). By using vignettes, it is possible to understand participants' reactions to these short stories. Interviews were structured in a month (between beginning on January and at the end of the January) by the telephone and face to face interactions. Based on the data gathering from interviews, these short vignettes were designed for future research purposes in this area. Personal characteristics are the independent variables for this research; on the other hand, resilient leader behavior is the dependent variable. 


\subsection{Vignette Development and Vignette Samples for This Research}

Basketball coaches and coach assistants who are the key executives in leading teams are selected to be interviewed.

As it was shown in Table 1, a number of interviewees are 8. All of the participants are male. 5 of them are in the coach assistant position, 3 of them are in the coach position.

Table 1: Summary of Interviews

\begin{tabular}{|l|c|c|}
\hline Position & Number of Participants & Communication Channel \\
\hline Coach & 2 & Telephone \\
\hline Coach & 1 & Face to Face \\
\hline Coach Assistants & 3 & Telephone \\
\hline Coach Assistants & 2 & Face to Face \\
\hline
\end{tabular}

\section{FINDINGS AND DISCUSSIONS}

In Table 2, there are frequencies about personality characteristics that interviewees mentioned in the interview. Mostly stated and discussed characteristics are being optimistic, self-efficacy and self-esteem. These characteristics are so selected as manipulated variables in these vignettes.

Table 2: Findings about Personality Characteristics

\begin{tabular}{|c|c|}
\hline Personality Characteristics & Frequency \\
\hline Optimism & $\mathrm{V} V \mathrm{~V} V \mathrm{~V}$ \\
\hline Self-efficacy & $\mathrm{V} V \mathrm{~V} V \mathrm{~V}$ \\
\hline Self-esteem & $\mathrm{V} \sqrt{ } \sqrt{ }$ \\
\hline Extraversion & $\mathrm{VV}$ \\
\hline Self-awareness & $\mathrm{V} \mathrm{V}$ \\
\hline Patient & $\mathrm{V}$ \\
\hline Openness & $\mathrm{V}$ \\
\hline Empathy & $\mathrm{V} \mathrm{V}$ \\
\hline
\end{tabular}

Three vignettes were developed and constructed based on the findings of the interviews with coaches and coaches' assistants. Related with the findings, three personality characteristics (optimism, self-efficacy and selfesteem) are determined, checked and manipulated in the vignettes. Only one personality character was manipulated in each vignette. In each vignette, there is a main topic which is about the resilient leader behavior. Participants were asked to imagine that they were the coach in the short story presented below:

\section{Vignette 1}

A is a coach in a basketball team. Players can't get their salaries for a while in this team. Team management made a mistake while they were setting their budget for this season. Player would have a new agreement with one of the other teams and would leave based on their contracts with their own team. How will you behave if you were $A$ ?

In vignette 1, the challenge is the budget estimate of the basketball team. In this short story, players would be free based on their contracts with their team when they didn't take their salaries in a period. Manipulated personality character is optimism in this case.

\section{Vignette 2}

$A$ is a coach in a basketball team. The most scorer player was injured in an important competitor against the strong opponent team. After this time, team was going down on the scoreboard. How will you behave if you were $A$ ?

In vignette 2 , the challenge is the injury of a player and going down in the basketball game. Manipulated personality character is self-esteem in this case. 


\section{Vignette 3}

A is a coach in a basketball team. He was recently transferred to this team. Previous coach was so successful and transferred to one of the biggest team in the international area. How will you behave if you were A?

In vignette 3 , the challenge is changing work environment and culture for the coach in the team. Everyone has also big expectations for him. Manipulated personality character is self-efficacy in this case.

\section{CONCLUSION}

Resilient leaders have ability to overcome challenges and turn them to opportunities. They can also accomplish their task easily, regulate emotions and solve others' problems. They have more proactive approaches than the others. Therefore, being resilient can be single factor for change and crisis management. Resiliency has a meaning of being flexible, being optimistic and bounce back from risk, stress or uncertainty. The purpose of this study is to determine the personal characteristics of resilient leaders by using vignettes.

The current study contributes our understanding of the personal characteristics of resilient leader in the sample of basketball organizations. One of the other purposes of this study is to develop a valid and reliable instrument to measure resilient leader behavior for future studies in this area. Basic characteristics as optimism, self-efficacy, self-esteem that affect the resilient leader behavior were determined according to the findings of structured interviews with basketball coaches and coach assistants. Three vignettes were developed by manipulating coaches' personal characteristics. In each vignette, there is only one person (coach), one challenge and one manipulated variable (personality character).

\section{Limitations and Further Research}

There are several limitations that should be associated for this study. Firstly, when it compared with the semistructured and unstructured interviews, structured interviews have the low popularity and participation. Participants may feel that they had to answer the questions in a limited time. Secondly, as suggesting vignettes for this study, there is a lack of statistical data. There is also a limit to test these vignettes in a sample. In further studies especially in sports organizations, developed vignettes should be tested and evaluated. In this sample, all participants that were interviewed are male. Women leaders' personal characteristics can be differentiated when they were compared with men.

\section{REFERENCES}

Avey, J. B., Wernsing, T. S. and Luthans, F. 2008, Can Positive Employees Help Positive Organizational Change, The Journal of Applied Behavioral Science, 44, 1, 48-70

Avey, J. B., Luthans, F. and Youssef, C. M. 2009, The Additive Value of Positive Psychological Capital in Predicting Work Attitudes and Behaviors, Journal of Management, http://jom.sagepub.com/content/early/2009/03/17/0149206308329961.full.pdf+html (Accessed 14 January 2014)

Avolio, B. J., Gardner, W. L 2005, Authentic Leadership Development: Getting to the Root for Positive Forms of Leadership, The Leadership Quarterly, 16, 315-338.

Boin, A. and Eeten, M. G. 2013, The Resilient Organization, Public Management Review, 15, 3, 429-445.

Campbell-Sills, L., Cohan, S. L. and Stein, M. B. 2006, Relationship of Resilience to Personality, Coping and Psychiatric Symptoms in Young Adults, Behavior Research and Therapy, 44, 585-599.

Coutu, D. L. 2002, How Resilience Work. Harvard Business Review, May, 46-55.

Earvolino-Ramirez, M. 2007, Resilience: A Concept Analysis, Nursing Forum, 42, 2, April-June, 73-82.

Friborg, O., Barlaug, D., Martinussen, M., Rosenvinge J. H. and Hjemdal O. 2005, Resilience in Relation to Personality and Intelligence, International Journal of Methods in Psychiatric Research, 14, 1, 29-42.

Grant, A. M., Gino F. and Hoffman, D. A. 2011, Reversing the Extraverted Leadership Advantage: The Role of Employee Proactivity, Academy of Management Journal, 54, 3, 528-550. 
Hamel, G. and Valikangas, L. 2003, The Quest for Resilience. Harvard Business Review, 81, 9, 52-63.

Harland, L., Harrison, W. Jones, J. R. and Reiter-Palmon, R. 2004, Leadership Behaviors and Subordinate Resilience, Journal of Leadership and Organizational Studies, 11, 2, 2-14.

Hartman, J. L., Turner, M. G. Daigle, L. E. Exum M. L. and Cullen F. T. 2009, Exploring the Gender Differences in Protective Factors, Implications for Understanding Resiliency, International Journal of Offender Therapy and Comparative Criminology, 53, 3, $249-277$.

Kleiman, E. M., Beaver, J. K. 2013, A Meaningful Life is Worth Living: Meaning in Life as a Suicide Resiliency Factor, Psychiatry Research, 210, 934-939.

Luthans, F., Avolio, B. J., Avey, J. B. and Norman, S. M. 2007, Positive Psychological Capital: Measurement and Relationship with Performance and Satisfaction, Personnel Psychology, 60, 541-572.

Luthans, F., Vogelgesang, G. R. Lester, P. B. 2006, Developing the Psychological Capital of Resiliency, Human Resource Development Review, 5, 1, 25-44.

Luthans, F., Youssef, C. M. Avolio, B. J. 2006, Psychological Capital: Developing The Human Competitive Edge, Carry, NC, USA: Oxford University Press.

Luthans, F., Luthans, K. W. and Luthans, B. C. 2004, Positive Psychological Capital: Beyond Human and Social Capital, Business Horizons, 47, $1,45-50$.

Luthans, F., J. B. Avey and J. L. Patera 2008, Experimental Analysis of a Web-Based Training Intervention to Develop Positive Psychological Capital, Academy of Management Learning and Education, 7, 2, 209-221.

Norem, J. K., Chang, E.C. 2002, The Positive Psychology of Negative Thinking, Journal of Clinical Psychology, 58, 9, $993-1001$.

Patterson, J. L., Kelleher, P. 2005, Resilient School Leaders, Strategies for Turning Adversity into Achievement, Library of Congress Publication, USA.

Pulley, M. L., Wakefield, M. 2002, Building Resiliency: How to Trive in Times of Change, Center for Creative Leadership, NC, USA.

Robertson, I., Cooper, C. L. 2013, Resilience. Stress and Health, 29, 175-176.

Sarkar, M., Fletcher, D. 2013, How Should We Measure Psychological Resilience in Sport Performers?. Measurement in Physical Education and Exercise Science, 17, 264-280.

Siou, O. , Hui, C. H. Philips, D. R. Lin, L. Wong, T. Shi, K. 2009, A Study of Resiliency Among Chinese Health Care Workers: Capacity to Cope With Workplace Stress, Journal of Research in Personality, 43, 770-776.

Stoltz, P. G. 2004, Building Resilience for Uncertain Times, Leader to Leader, 16-20.

Vickers, M. H., Kouzmin, A. 2001, Resilience in Organizational Actors and Rearticulating Voice. Public Management Review, 3, 1, 96-119.

Walumbwa, F. O., Avolio, B. J., Gardner, W. L. , Wernsing, T. S. , Peterson S. J. 2008, Authentic Leadership: Development and Validation of a Theory Based Measure. Journal of Management, 34, 1, 89-126.

Youssef, C. M. 2007, Positive Organizational Behavior in the Workplace: The Impact of Hope, Optimism and Resilience. Journal of Management, 33, 5, 774-800. 